\title{
TFP Technology As Theadvanced Method Of Manufacture Of 3D Reinforced Preforms Frompolymer Composite Materials
}

\author{
${ }^{1}$ Nelyub Vladimir Aleksandrovich, ${ }^{2}$ Polikarpova Irina Aleksandrovna*, ${ }^{3}$ Borodulin Aleksey \\ Sergeevich, ${ }^{4}$ Orlov Maksim Andreyevich, ${ }^{5}$ Solodilov Vitaly Igorevich \\ ${ }^{1} \mathrm{PhD}$, Director of Intersectoral Engineering Center «Composites of Russia» Bauman Moscow State Technical \\ University, Moscow, Russia, \\ ${ }^{2}$ Engineer, Bauman Moscow State Technical University, Moscow, Russia, \\ ${ }^{3} \mathrm{PhD}$, Deputy Director of Intersectoral Engineering Center «Composites of Russia» Bauman Moscow State \\ Technical University, Moscow, Russia \\ ${ }^{4}$ Head of Laboratory, Bauman Moscow State Technical University, Moscow, Russia, \\ ${ }^{5} \mathrm{PhD}$, Head of Laboratory, Semenov Institute of Chemical Physics, RAS, Moscow, Russia \\ 1'mail@emtc.ru, ${ }^{2}$ ipolikarpova@emtc.ru, ${ }^{3}$ asb@emtc.ru, ${ }^{4}$ maksim.orlov@emtc.ru, ${ }^{5}$ vital-yo@yandex.ru
}

Article History: Received: 11 January 2021; Accepted: 27 February 2021; Published online: 5 April 2021

\begin{abstract}
This paper contains an overview of world trends in the development of the TFP technologyenabling 3D printing of carbon fiber reinforced plastics. The review of the equipment used for the automated preformpatching is included. Primary factors restraining the large-scale implementation of the TFP technology in the manufacture are identified, and prospective research trends for further development of the technology are proposed.
\end{abstract}

Keywords: Tailored fiber placement, polymer composite materials, fiber preform, 3D reinforced composites, automated patching.

\section{Introduction}

The field of application of composite materials in various industries (aircraft, space industry, shipbuilding, energy, construction, mechanical engineering, etc.) is growing from year to year.Currently, 3D reinforced composites are gaining ground in the manufacture of parts and structures from polymer composite materials (PCM). They areproduced based on 3D fiber preformswithvarious orientations and angles of reinforcement during themanufacture of the preform and with the complex shape ability[1-6].In addition to netting, 3D weaving and knitting, modern methods of manufacture of 3D reinforced preforms [7-11]include the Tailored fiber placement technology (TFP), a directional fiberlaying on the base materialin thespecified path (Figure 1) [12, 13]. Reinforcing fiber (roving) is sewn to the base material moving in the $\mathrm{x}$ - and $\mathrm{y}$-directions to perform a zigzag stich usingan additional thread. After laying of the appropriate layers with fiber strands, the finished fiber preform is placed into the equipmentand impregnated with a polymer binder, and then cured.

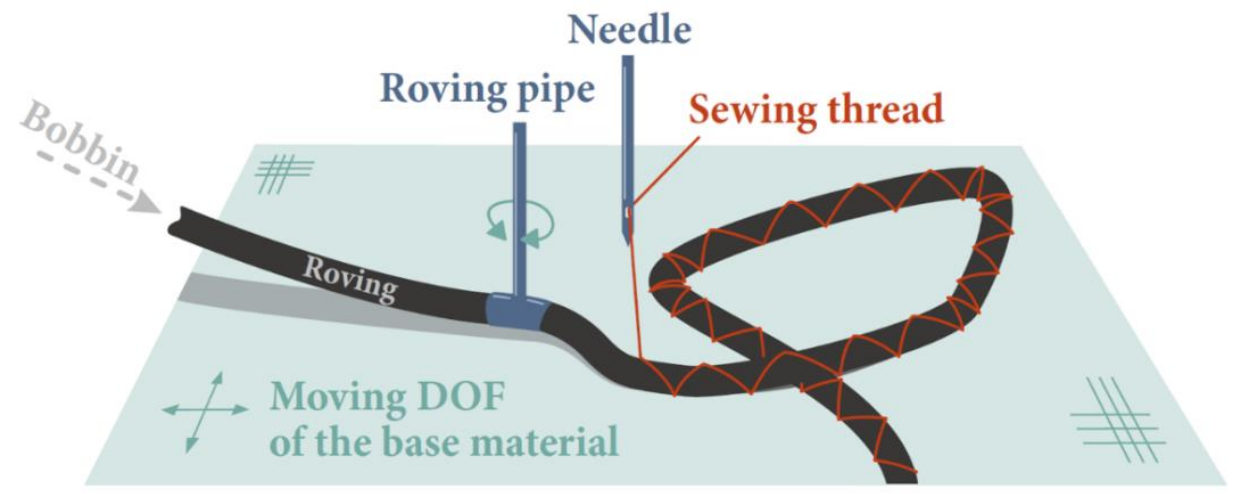

Figure1 - Scheme of the TFP-process 


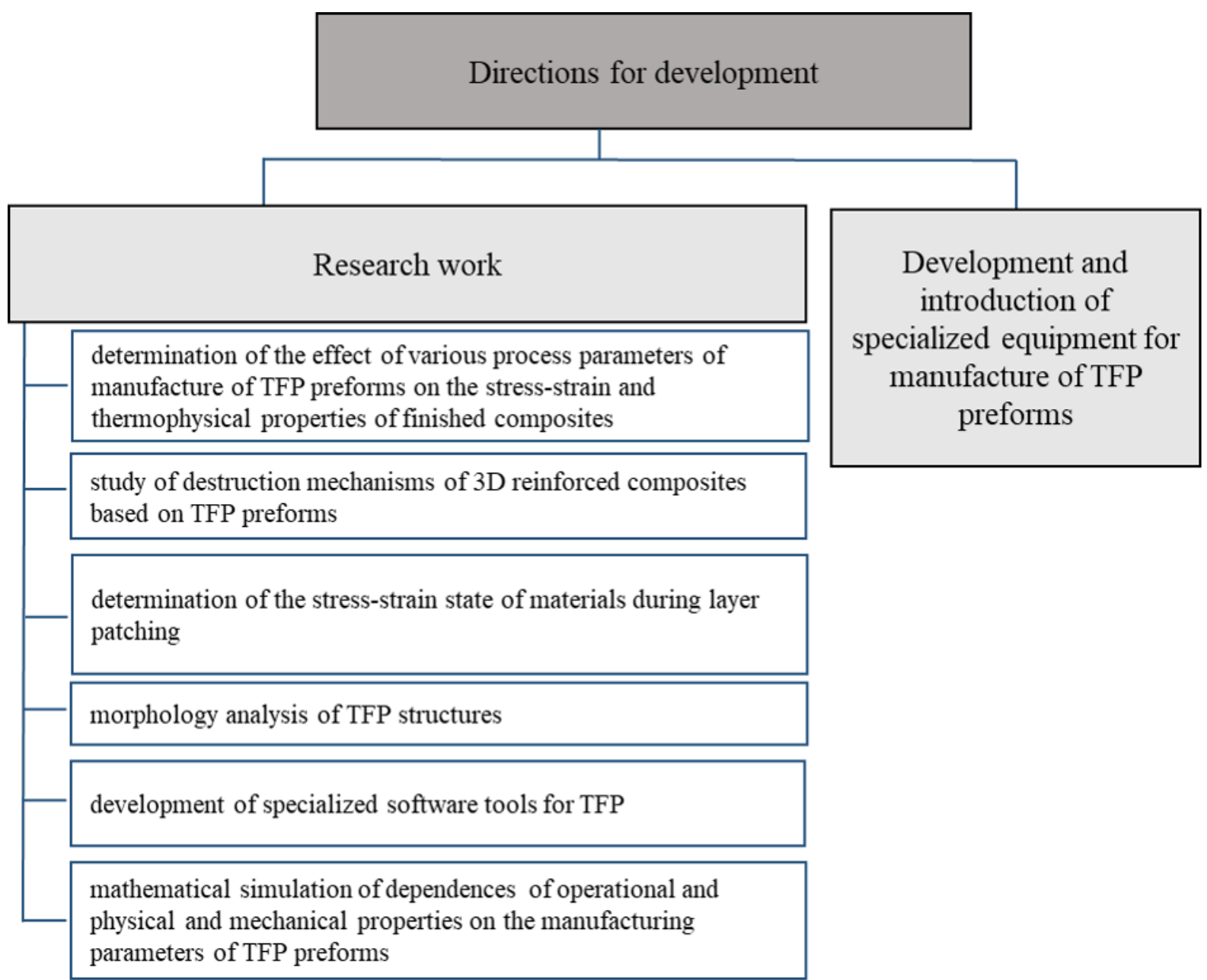

Figure2 - Promising directions of TFP-technology development

The advantages of the method include fiberpatching based on the load distribution vectors and the possible creation of local reinforcement zones -laying of additional fiber strands can be used to form special reinforcement areas of the zones subject to a special load. Furthermore, the TFP technologyenables the creation of integrated structures without auxiliary operations andthe use of the material's propertyto the full. The highly automated manufacturing process involving several embroidery heads makes the technology attractive for the serial production of 3D reinforced blanks.TFP preforms are widely used abroad -certain companies have mastered the process and introduce it into production [14-17]. However, despite the clear advantages of directional patching, composites and products based on the TFP technology are not available in the Russian market. This can be explained by the ignorance of most researchers and developers and the poor coverage of the method in the Russian scientific and technical literature, which results in the almost complete absence of scientific research. In view of the foregoing, this paper is aimed at the review and full assessment of the state-ofthe-art and systematization of the available materials in the field of manufacture of $3 \mathrm{D}$ reinforced composites based on TFP preforms.

\section{Development TFP in the world}

The TFP technology was developed in the Leibniz Institute of Polymer Research Dresden (Leibniz-Institut für Polymerforschung Dresden e. V. - IPF) in the 1990s [12, 18, 19]. In 1992-1998, IPF mastered and improved the method [12, 20-22]. To create curvilinear patterns, preforms were first produced by manual directional laying of the roving. This principle was further adapted and implemented for industrial embroidery machines. In 1998, Hightex Verstärkungsstrukturen (Klipphausen, Germany) involved in the manufacture of TFP preformswas createdas part of IPF. FilaCon (Winterlingen, Germany) began the production of embroidery machines for the manufacture offiber blanks using the TFP technology. Currently, FilaCon is a registered trademark of Tajima $\mathrm{GmbH}$.

In 2001, Hightex jointly with Eurocopter (now Airbus Helicopters, Donauwörth, Germany) began to supply TFP preform-based spars for NH-90 helicoptersto NH Industries (Aix-en-Provence, France). 
From 2003 to 2007, the so-called KRAFT, EMIR and ROVING projects [18] had been developed. They were put into practice in the form of theTFP technologyused for the production of window frames with $\Omega$-shaped cross-section and Z-frames for the fuselage of Airbus Hamburg A350XWB aircraft (since 2010, window frames are in serial production).

From 2005 to 2008, IPF employees had conducted research in the field of optimization of thefiber reinforced composite material using the basics of bionics (BIOTEXproject). Project developers desired to simulate the manufacture of lightweight structures from PCM using the example of various natural structures (trees, grass and bones) with the formsproperly adapted to specific loads. The purpose was to achieve the maximum hardness and strength by orienting fibers in the main directions of stress. To gainthe best result and uniform stress distribution with the lowest material consumption, the first computer programmes were developed for simulation and optimization of properties of theprospective composite based on the TFP technology. Cetex Institute, Daimler Chrysler AG, Herzog, SAERTEX, SINTEC, Volkswagen acted as partners.

In 2009, Q Point Composite GMBH (Dresden, Germany) was createdas part of IPF. It used directional fiberlaying in serial production of parts for the aircraft industry (window frames for Airbus A350, spoilers for Airbus A330). In 2011-2012, IPF in partnership with Avana Industries, GMI AERO, IDEC, Q Point, Elektronik, Tecnalia, Tajima and others launchedthe EMBROIDERY project. Itstipulated the development of the TFP preformsmanufacturing technology for a reusable vacuum infusion heating membrane[15] and an integrated heating layer in RTM plantsto ensure faster heating/cooling and lower energy consumption [16].From 2012 to 2015, IPF employees jointly with 26 companies of the textile and composite industries had been engaged in patching of strain gauges, lighting systems and wires using the TFP technology and in the development of 3Dthermoplastic composites. In 2013, IPF manufactured and tested the17-blade rotor ofthe blade-integrated disk design, operating at higher rotation speeds than the aluminum analogue. By 2015,carbon fiber reinforced KUKA KR 180 RA robotic arm had been manufactured. It should be noted that the manufacture of TFP preforms mainly involves the use of carbon fibers due to their increased stress-strain properties compared to other inorganic fillers. However, other types of fiberfillers, such as glass and basalt and combinations thereof, can be usedas the reinforcement material during patching.

\section{Evolution of the support layer for tfp-preforms}

Carbon or glass fabrics, thermoplastic films [24], elastomer sheets and water-soluble substrates are used as the base material (support layer) on which the first preform layer is fixed. Woven materials were originally used in the manufacture of tfp-preforms. Before the finished preform is placed into the equipment, the woven material of the base layer extending beyond the edge of the fiberblank is cut or torn off.In the first case, the support layer becomesthe part of the fiberblank. It performs no functions, but increases the productweight. This is especially crucialwhen several fiberblanks are placedon each other. In addition, separation may occur in the area of base layers of the finished composite part.In this regard, the base materialisrecommended for use as an auxiliary materialto be removed because of the absence of the functional load. However, another problem arises -in case of base separation, the mechanical damage to reinforcing fibers, violation of the blank integrity and geometry are highly probable. Joern Paul and Eberth Ulrich obtained the patent for the method of producing single and multilayer preforms using the TFP technology. They proposed to fixthefiberblank before the removal from the elastic and flexible base, for example, a sheet of rubber or silicone [25]. This technical solution allows to preventunnecessary displacement of fiberstrands to a significant extent.Thermoplastic powder that melts at the low temperature, curable adhesive, etc. can be used for strand fixation. The authors of [26] propose to applya separationlayer of a thin polytetrafluoroethylene film on the base layer followed by fiberpatching thereon. Then a fiberblank is placedinto a fixing device for melting fixing threads by heating. The separation layer of the nonadhesive material enables the easy detachment of the base layer from the fiberblank without damagingfiber strands or preform deformation. In recent years, water-soluble substrates easily removed from fiberpreforms by washing have been used as the support layer [27, 28]. Water-soluble polymeric materials, for example, based on $100 \%$ polyvinyl acetate(PVA), can be used as the substrate. The solvent water is completely removed from the fiberblank by drying.

The perspective of water-soluble substrates in comparison with the currently used woven materials, elastomers and films is explained by the fact that the washout of such substrates is a simple, affordable and easily feasible technological operation, in which the integral structure of the tfp-preform with the geometry of the final product is preserved. The water-soluble substrate is removed from the fiber blank without disturbing its configuration and without causing damage to the fibers.

\section{Stitching threads for tfp-preforms}

As forthe stitching thread materials, glass, poly(p-phenylene terephthalamide) (PPTA), polyamidobenzimidazole (PABI), polyamide nylon and capronfibers, high-strength and high-modulus aramid threads, etc. are currently used. Scientistsconducted numerous research to study the effect of various types of threads andstitching parameters on the properties of carbon fiber reinforced plastics; obtained documents of title for the results of 
intellectual activity, and gained experience in the manufacture and testing of TFP preforms-basedproducts for the improvement of physical and mechanical characteristics.[29] specifiesthat reinforcing fibers are patched onto the substrate using chemically or thermally free-melting fixing threads, which are initially used for fixation of reinforcing fibers on the substrate. Theyare subsequently dissolved, thus not affecting the mechanical properties of the structure of the reinforcingfiber. The authorsof [29] studied the effect of the type of the stitching thread on the carbon content in finished PCM samples and their mechanical properties. Unidirectional TFP blanks made of Tenax HTS 5331-24K carbon fiber were manufactured on the substrate material (fiberglass with the density of $80 \mathrm{~g} / \mathrm{mP}^{2} \mathrm{P}$ ) using various stitching threads to fix the roving.The fixing threads represented Grilon K85 $110 \mathrm{dtex}$ free-meltingmultifilament threads with the standard melting point of $85{ }^{\circ} \mathrm{C}$, Transfil 56 dtex polyamide unit thread, Serafil 100 dtex polyamide thread and polyester filament typically used for manufacturing multiaxial fabrics (textured PSE 76 dtex). It should be noted that, unlike the first type of thread, the latter threads do not melt at the temperatures reached during further processing. As an additional option, Grilon K85 110 dtex reinforcing fiberswere stitched on the Super Release Blue detachable fabric. Carbon fiber rovings were placed parallel to each other at the distance of $3.375 \mathrm{~mm}$ and fixed on thebase with the zigzag stich $4 \mathrm{~mm}$ long and 2 $\mathrm{mm}$ wide, a total of 4 unidirectional layers one above the other.Two of the reinforcing fiber structures or semifinished products were then laid into thepattern equipment, impregnated with HexFlow RTM6 multicomponent resin (Hexcel, USA), and cured. Finished laminate panels were selected in the direction of fibers and subjected to tensile and compression tests. The comparison of physical and mechanical properties of different samples showed that the significant increase in the stress-strain properties was achievedwith Grilon threads -the tensile strength is increased by $30 \%$, compressive strength by $23 \%$, tensile modulus by $8 \%$ and pressure modulus by $26 \%$.

In [28, 30] authors used aramid thread Rusar-S 29,4 tex (Thermotex LLC, Mytishchi, Russia), polyamidobenzimidazole thread Armos 60 tex ( Lirsot LLC, Mytishchi, Russia), poly (p-phenylene terephthalamide) Armalon 7,9 tex (Tema-M LLC, Mytishchi, Russia) as sewing threads in the manufacture of fibrous preforms. When stitching preforms aramid threads was achieved the greatest increase in shear strength of finished carbon fiber - up to $15 \%$.

Speckenheuer et al. presented the first results of research on the possibility of using hybrid threads for the manufacture of tfp-preforms, allowing to obtain high-quality composites. The commingled yarns are made by simultaneous spinning of E-glass fibers (GF) and Polybutylenterephthalat (PBT) filaments with different sizings and have increased adhesion to the matrix [31].

Thus, it should be noted that currently TFP technology applies standard threads used in the textile and chemical industries. Among them, the most promising are aramid and hybrid threads, which allow to obtain composites with increased physical and mechanical properties. Special threads for TFP have not been inventedyet, so the development and use of new yarns and fibers is of considerable interest.

\section{Physical and mechanical properties of stitched reinforced plastics}

Mattheij et al.presented [32] the results of studies of the influence of orthogonal reinforcement of preforms on the physical and mechanical properties of PCM samples as well. The preforms were obtainedby carbon fiber roving patch, sewn with aramid, polyethylene and polyester fibers and impregnated with a binder using vacuum assisted resin transfer moulding (VARTM). Besides, the experimentswere focused onthe effect of the thread tension, the distance between adjacent paths and the stitch length.The results showed that aramid fiberstitching reduces the tensile and bending strength of samples by about 3-8\%. No significant increase in the impact strength was observed. In paper [31], SpinCom hybrid threads [33] consisting of glass and polybutylene terephthalate fibers were used to produceTFP preforms of thermoplastic composite samples. The possible use of hybrid threads to produce thermoplastic composites based on TFP preformswas demonstratedon the example of a bicycle saddle.The test results showed that the combination of the size-adapted SpinCom combination yarn and the Tailored Fiber Placement technology allows to obtain high-quality thermoplastic composites with the precise location and efficient use of the material. The studies of the effect of the stitch length and width and the type of thread on the degree of waviness (unevenness) of the material, the volume content of fibers, and the laminate hardness and strength were conducted in $[13,34,35]$.

A great number of papersdescribe the studies of carbon fiber reinforced plastics with holes. For example, the use of the TFP technology for the manufacture of plates with holes and the possibility of increasing strength near the holes were studied by Crothers et al.in [22]. In [36], Gliesche et al. studied the use of the automated roving patch technology to identify the effects of additional local reinforcement near the hole. For this purpose, local carbon fiber patch was laid on the quasi-homogeneous multiaxial fabric with the hole for additional reinforcement around the hole. The experiments showed that the holes in plates made by traditional pressing reduce the tensile strength up to $61 \%$ of the strength of the holeless sample. However, additional reinforcement of the preform by patching allows to achieve the strength of samples up to $94 \%$ of the strength of the holelesssample with a slight increase in weight. El-Dessouky et al.studied the technology of manufacture oflaminated plastics with the hole based on the thermoplastic binder [37]. The authors of [38] presented the results of studies of samples with holes 
in tension and cyclic tests. The samples were made from multiaxial fabrics, woven preforms and using the automated roving patch method. Three different reinforcement patternswere studied. As a result of cyclic tests, three of four woven patterns were destroyed; other samples remainedintact. The authors noted that the strength of samples with the laying pattern $\left[ \pm 45^{\circ}\right]$ was lower than for holeless samples, but higher than for samples with the laying pattern $\left[0^{\circ} ; 90^{\circ}\right]$ and $\left[+45^{\circ} / 0^{\circ} /-45^{\circ}\right]$. In [39], Koricho et al. studied the effect of different roving patterns on the strength and crack resistance of samples with the hole. Samples with the hole produced by automated roving patch had a tensile strength of about $92.7 \%$ of the strength of the holeless sample, while samples with the drilled hole had a strength of $38 \%$ of the strength of the holeless sample.

Papers focused on simulation and optimization of curvilinear fiber-reinforced composites based on TFP preforms are of interest. Albers et al. [40] and Spickenheuer et al. [41] made the first attempts to separate optimization of the curvilinearfiber-reinforced composite based on the TFP technology from real numerical models in order to limit the number of required design variables and make them independent of the FEM mesh resolution. Spickenheuer et al. proposed a software system that combines a stress-strain state module and a roving patch programme module [41].Uhlig et al. presented the results of calculation of stresses of the material structure during TFP, the uniaxial tension using the finite element method [34]. To assess the specific features of the TFP process, a mesoscale model was used according to the author's recommendations. [42] presentsthe concept of numerical simulation of TFP preforms - Direct Fiber Path Optimization (DFPO). Its main achievement is the local optimization of the angle and thickness of fibers at each finite element along the base mesh. A new optimization approach was demonstrated and numerically evaluated on the example of the sample with a through hole under tensile loading. DFPO is a real optimization procedure that considers not only local, but also global features of the sample. Compared to other optimization methods in which the elementary fiber orientations and thickness values are optimized without correlations caused by infinite fibers, in DFPO each fiberplacement patterncovered by each optimization iteration is already easily producible and requires no further adaptation.

Thesignificant disadvantage of TFP technology is the manufacture of preforms notthicker than $8-10 \mathrm{~mm}$ per process operation due to the limited technical capabilities of embroidery equipment and the needlelength. Besides, the operating principle of embroidery machines stipulates the connection of each successive patch layer not only to each other, but also to the very first layer: the stitching zigzag thread in the third direction always passes through the first layer. The more layersare made, the more needle punctures each previous preform layers have. The first layer features the maximum damage to the base fiber. This adversely affects the strength properties of the finished composite due to the multiple destruction offibers during the manufacture of the preform.

Despite this, physical and mechanical properties of stitch carbon fiber reinforced plastics correspond to the properties of traditional polymer materials and their shear strength is even higher. In addition to achieving optimal elastic-strength properties, TFP technology allows to create local reinforcements (for example, around the holes), to combine a variety of materials and reinforcement directions.

\section{Development of TFP technology in Russia}

In Russia, the TFP technology of manufacture of 3D reinforcedpreforms using PCM is still largely unknown, but some attempts are made in this field [43-46]. The primary and almost the only restraining factor for the large-scale introduction of TFP preforms-basedcomposites into production not only in Russia but also abroad is the lack of specialized equipment.Currently, preform patching is carried out on industrial CNC embroidery machines used in the textile industry. For example, Hightex Verstarkungsstrukturen $\mathrm{GmbH}$ (Germany) uses own sewing machines (Hightex) for manufacturing TFP preformsof window frames and floor elements for Airbus A350. ShapeTex ${ }^{\mathrm{TM}}$ (Witney, Oxfordshire, England) uses ZSK Stickmaschinen embroidery machines (Germany) in its studies, and the Leibniz Institute for Polymer Research(Dresden, Germany), the Institute of Aircraft Design (IFB) (Stuttgart, Germany), and Centreof Composite Technology KNRTU-KAI (Kazan, Russia) use Tajima sewing machines (Tajima GMBH, Japan) in their developments, which are supplied by LayStitch $^{\mathrm{TM}}$ (Michigan, USA) and Filacon Systems (Winterlingen, Germany).These embroidery machines were adapted for the composite industry and enable the use of carbon, glass, polyamide and aramid threads as patch materials. It should be noted thatthe high cost prevents the introduction of the equipment for manufacturing 3D reinforced preforms into the Russian market. For example, the simplest industrial embroidery machine Tajima TCMX - 601 (Japan) with the working area of 460x550mm costs more than $\$ 16,000$, a singlehead embroidery machine JCW 0100-500 (ZSK Stickmaschinen, Germany) with the working area of 700x500 $\mathrm{mm}$ costs more than $\$ 20,000$. The cost of a more powerful, advancedembroidery machine adapted for patching of composite materials ZSK SGFA0112-1300 (ZSK Stickmaschinen, Germany) with a larger working area of 1300x1400mm and increased speed ranges between $\$ 50,000-55,000$.

Bauman Moscow State Technical University is developing an automated complex for the manufacture of tfp-preforms with less damage to the fibers. The new complex will eliminate the shortcomings of existing embroidery machines and will allow to obtain volume-reinforced preforms with a thickness of at least $50 \mathrm{~mm}$ in one technological operation. At the same time, the improvement of technological and operational characteristics 
of composites will be achieved through the use of a fundamentally new scheme of fastening the fiber to the substrate and the principle of operation.

\section{Conclusion}

The review of the scientific and technical literature suggests that currently there are wide opportunities for scientific research and technical solutions in the field of manufacture of $3 \mathrm{D}$ reinforced composites based on TFP preforms. Two main directions for further development of the TFP technology can be considered (Figure 2): on the one hand, development and introduction of new specialized equipment (high-tech and commercially available), on the other hand, research work, the results of which will allow to bring the TFP technology to a new level and create PCM parts and structures having high physical and mechanical properties and technical and economic performance.

\section{Acknowledgments}

This study was supported financially by the Ministry of Science and Higher Education of the Russian Federation in the framework of the Program for Research and Development in Priority Areas of Development of the Russian Scientific and Technological Complex for 2014-2020, subsidy agreement No.14.574.21.0160 of September 26, 2017, unique agreement identifier RFMEFI57417X0160.

\section{References}

1. Bogdanovich A.E. Multi-scale Modeling, Stress and Failure Analyses of 3-D Woven Composites// Journal of Materials Science. - 2006. - Vol. 41. - No20. - pp. 6547-6590.

2. Donetsky K.I., Khrulkov A.V., Kogan D.I., Belinis P.G., Lukyanenko Yu.V. Use of Three-Dimensional Reinforcing Preforms during the Production of Polymer Composite Products // Aviacionnye materialy $\mathrm{i}$ tekhnologii. - 2013. -No1. - pp. 35-39 (in Russian).

3. Kovalenko O.N., Tuvin A.A.Advanced textile technologies for manufacturing of high performance composites // Fizika voloknistyh materialov: struktura, svojstva, naukoemkie tekhnologii i materialy (SMARTEX). - 2016. - Volume 2. - No1. - pp. 113-117 (in Russian)

4. Bogdanovich A. E. and Mohamed M. H. Three-dimensional reinforcements forcomposites // SAMPE Journal. - 2009. - Vol. 45. - pp. 8-28.

5. A.P. Mouritz. Three-dimensional (3D) fibre reinforcements for composites // Composite Reinforcements for Optimum Performance. - 2011. - pp. 157-199.

6. Rajeev Varshney, Amit Madahar. Innovations in Textile Composite Designing and Their Applications // International Journal of Computer Applications. Proceedings of ICAET 2015, Number 12 (ISBN: 973-9380888-44-1). - 2015.

7. N. Ishmael, A. Fernando, S. Andrew, L. W. Taylor. Textile technologies for the manufacture of threedimensional textile preforms // Research Journal of Textile and Apparel. - 2017. - Volume 21. - No.4. pp. 342-362

8. M. K. Bannister. Development and application of advanced textile composites // Proceedings of the Institution of Mechanical Engineers Part L Journal of Materials Design and Applications. - 2004. Volume 218. - issue 3. - pp. 253-260

9. Jürgen Brandt, Andreas Geßler, Jürgen Filsinger. New approaches in textile and impregnation technologies for the cost effective manufacturing of CFRP aerospace components // ICAS 2002 CONGRESS. - 2002

10. M.H. Mohamed, A.E. Bogdanovich, L.C.Dickinson, J.N. Singletary and R.B. Lienhart. A New Generation of 3D Woven Fabric Preforms and Composites // SAMPE Journal. - 2001. - Vol. 37. - No. 3. - pp. 8-17.

11. Natalie Ishmael, Anura Fernando, Sonja Andrew, Lindsey Waterton Taylor. Textile technologies for themanufacture of three-dimensionaltextile preforms // Research Journal of Textile andApparel. - 2017. Vol. 21. - No. 4. - pp. 342-362

12. Mattheij K., Gliesche K., Feltin D. Tailored fiber placement - mechanical properties and applications // Journal of Reinforced Plastics and Composites. - 1998. - Volume 17. - issue 9. - pp. 774-786.

13. Uhlig K., Bittrich L., Spickenheuer A., Almeida Jr. Waviness and fiber volume content analysis in continuous carbon fiber reinforced plastics made by tailored fiber placement // Composite Structures. 2019. - Volume 222. - p.110910

14. José Humberto S. Almeida Jr., Lars Bittrich, Axel Spickenheuer. Fiber path optimization of a composite break booster manufactured via tailored fiber placement // NAFEMS Seminar: Simulation Driven Engineering. - 2017. - pp. 97-103

15. Carosella S. Tailored Fibre Placement - Merging stitching and fibre placement technologies// ICS Europe, JEC Paris. 2012 
16. Carosella S. Tailored Fibre Placement - an option for automated high volume Preform Production// Symposium on Automation of Advanced Composites and its Technology, materials of conference SAMPE Europe Symposium 2012 (SEMAT). - 2012. - pp. 52-58

17. A. Spickenheuer, C. Scheffler, L. Bittrich, R. Haase, D. Weise, D. Garray, G. Heinrich. Tailored Fiber Placement in Thermoplastic Composites // Technologies for Lightweight Structures. - 2017. - Vol.1. No2. - pp. 114-127

18. H. Temment, R. Degenhardt and T. Raible. Tailored Fiber Placement Optimization Tool // Proceedings of the 25th Int. Congress of the Aeronautical Sciences, Hamburg, ICAS - 2006, pp. 576-583.

19. Ginger Gardiner. Tailored Fiber Placement: Besting metal in volume production//Plastic Technology. 2013. - №2

20. Gliesche K., Feltin, D. Beanspruchungsgerechte Textilkonstruktionen für composite-Bauteile, Technische Textilien//Technical Textiles. - 1995. - Vol. 38. - p.1050

21. Gliesche K., Feltin D. Technische Gesticke als kraftflußgerechte Textilkonstruktionen für FaserverbundBauteile // Konstruktion. - 1996. - vol. 48. - pp. 114-116

22. P. J. Crothers, K. Drechsler, D. Feltinc, I. Herszberga and T. Kruckenbergd. Tailored fibre placement to minimise stress concentrations // Composites Part A: Applied Science and Manufacturing. - 1997. - Vol. 28 - issue 7. - pp. 619-625

23. Uhlig K., Spickenheuer A., Bittrich L., Heinrich G. Development of a highly stressed bladed rotor made of CFRP using tailored fiber placement technology // Mechanics of Composite Materials. - 2013. - Vol. 49. - issue 2. - pp. 201-210

24. Hervé Grelin. Method for manufacturing a preform and its use in the manufacture of a composite part // Pat. EP 2599614 (B1). - 2013.

25. Joern Paul, Eberth Ulrich. Method for producing one- or multi-layer layer fibre preforms according to a TFP method // Pat. WO2007010052 (A1). - 2007

26. Joern Paul, Eberth Ulrich. Method of producing one- or multilayer fibrous workpiece using TFPtechnology, and back-up layer // Pat. WO2007010049 (A1). - 2007.

27. Joern Paul, Eberth Ulrich. Method for producing one- or multi-layer layer fibre preforms, fixing threads and a support layer // Pat. WO2007010051 (A1). - 2007

28. OrlovM.A., KalinnikovA.N., PolikarpovaI.A. Development of technology for creating preliminary blanks of gas turbine engine elements from polymer composite materials by automated carbon fiber stripe // Novye tekhnologii, materialy i oborudovanie rossijskoj aviakosmicheskoj otrasli: sbornik materialov Vserossijskoj nauchno-prakticheskoj konferencii s mezhdunarodnym uchastiem, Kazan. - 2018. - vol. 1. - pp. 270-275 (inRussian).

29. Gessler Andreas. Method for producing multilayer Tailored Fiber Placement (TFP) preform // Pat. WO0245932 (A1). - 2002.

30. Miheev P.V., Orlov M.A., Shatalov R.L., Verhov E.Yu. Effect of preform stitching with aramid threads on shear characteristics of the final carbon fiber product // Sistemnye tekhnologii. - 2015. - № 3 (16). pp. $37-42$ (in Russian)

31. Spickenheuer A., Scheffler C., Bittrich L., Haase R., Garray D., Heinrich G. Tailored fiber placement in thermoplastic composites // Technologies for Lightweight Structures. - 2017. - Volume 1. - issue 2. - pp. 114-127

32. Mattheij P., Gliesche K., Feltin D. 3D reinforced stitched carbon/epoxy laminates made by Tailored Fibre Placement // Composites part A: Applied science and manufacturing. - 2000. - Vol. 31. - issue 6. - pp. 571-581.

33. Wiegand N., Mäder E. SpinCom yarns - from reinforcement to functional fibers // Melliand China. 2016. - Volume 11. - pp. 22-26

34. Uhlig K., Tosch M., Bittrich L., Leipprand A., Dey S., Spickenheuer A., Heinrich G. Meso-scaled finite element analysis of fiber reinforced plastics made by Tailored fiber placement // Composite Structures. 2016. -Vol. 143. - pp. 53-62

35. Spickenheuer A., Leipprand A., Bittrich L., Uhlig K., Richter E., Heinrich G. Process-dependent material properties for structural simulation of composites made by tailored fibre placement // Proceedings of ECCM16 - 16 ${ }^{\text {th }}$ European conference on composite materials, Seville, Spain, 22-26 June 2014.

36. Gliesche K, Hubner T, Orawetz H. Application of the tailored fibre placement (tfp) process for a local reinforcement on an open-hole tension plate from carbon/epoxy laminates // Composites Science and Technology. - 2003. - Vol.63. - pp. 81-88

37. El-Dessouky H.M., Saleh M.N., Gautam M., Han G., etc. Tailored fibre placement of commingled carbon-thermoplastic fibres for notch-insensitive composites // Composite structures. - 2019. - Vol. 214. - pp. 348-358.

38. Uhlig, K., Spickenheuer, A., Gliesche, K., Karb, I. Strength of CFRP open hole laminates made from NCF, TFP and braided preforms under cyclic tensile loading // Plastics, Rubber and Composites. - 2010. 
- Vol. 39. - issue 6. - pp. 247-255

39. Koricho E.G., Khomenko A., Fristedt, Mahmoodul H. Innovative tailored fiber placement technique for enhanced damage resistance in notched composite laminate // Composite Structures. - 2015. - Vol. 120. - pp. 378-385.

40. A. Albers, N. Majic and D. Troll. Modeling approaches for the simulation of curvilinear fiber-reinforced polymer composites // Proceedings NAFEMS Seminar: Progress in Simulating Composites, Wiesbaden, Germany, 2011.

41. A. Spickenheuer, M. Schulz, K. Gliesche, and G. Heinrich. Using tailored fibre placement technology for stress adapted design of composite structures // Plastics, Rubber and Composites. - 2008. - Volume 37. No. 5-6. - pp. 227-232

42. L. Bittrich, A. Spickenheuer, J. H. S. Almeida, S. Müller, L. Kroll, G. Heinrich. Optimizing VariableAxial Fiber-Reinforced Composite Laminates: The Direct Fiber Path Optimization Concept // Mathematical Problems in Engineering. - 2019. -Volume 2019(3). - pp. 1-11

43. Khaliulin V.I., Khilov P.A., and Toroptsova D.M. Prospects of applying the tailored fiber placement (TFP) technology for manufacture of composite aircraft parts// Izvestiya vysshih uchebnyh zavedenij. Aviacionnaya tekhnika. - 2015. - No4. - pp. 127-132 (in Russia).

44. Hilov P.A., Gershtejn E. M., Sungatullin R.N. Prospects of application of TFP technology in the production of composite aircraft parts // Sbornik trudov konferencii «Problemy i perspektivy razvitiya aviacii, nazemnogo transporta i energetiki ANTE-2013». - 2013. - pp. 169-171 (inRussian).

45. Bezzametnova D.M. Application of TFP-technology in the manufacture of structures made of composite materials // Sbornik trudov konferencii «Problemy i perspektivy razvitiya aviacii, nazemnogo transporta i energetiki ANTE-2015». - 2015. - pp. 117-122 (inRussian).

46. Karimbaev T.D., Mezencev M.A., Ezhov A.Yu. Development and testing of the impeller of a centrifugal compressor from PCM, obtained with automatic stitch of carbon roving // Problemy i perspektivy razvitiya dvigatelestroeniya: materialy dokladov mezhdunarodnoj nauchno-tekhnicheskoj konferencii (12-14 September 2018). - Samara. - 2018. - pp. $42-43$ (in Russian). 